\title{
Two new endemic species of Bistriopelma (Araneae: Theraphosidae) from Peru, including a new remarkable horned tarantula
}

\author{
Micaela NICOLETTA ${ }^{1, *}$, Juan C. CHAPARRO ${ }^{2}$, Luis MAMANI ${ }^{3}$, José A. OCHOA ${ }^{4}$, \\ Rick C. WEST ${ }^{5} \&$ Nelson E. FERRETTI ${ }^{6}$ \\ ${ }^{1,6}$ Instituto de Ciencias Biológicas y Biomédicas del Sur (INBIOSUR-CONICET, UNS), \\ San Juan 670, Bahía Blanca (8000), Buenos Aires, Argentina. \\ ${ }^{1,6}$ Departamento de Biología, Bioquímica y Farmacia, Universidad Nacional del Sur, \\ San Juan 670, Bahía Blanca (8000), Buenos Aires, Argentina. \\ 2,3,4 Museo de Biodiversidad del Perú, Urbanización Mariscal Gamarra A-61, Cusco, Peru. \\ 2,3 Museo de Historia Natural de la Universidad Nacional de San Antonio Abad del Cusco, \\ Paraninfo Universitario (Plaza de Armas s/n), Cusco, Peru. \\ ${ }^{4}$ Facultad de Ciencias, Universidad Nacional de San Antonio Abad del Cusco, \\ Av. La Cultura 733, Cusco, Peru. \\ ${ }^{5} 6365$ Willowpark Way, Sooke, BC, Canada. \\ *Corresponding author: mmnicolettal@gmail.com \\ 2Email: jchaparroauza@yahoo.com \\ ${ }^{3}$ Email: luismamanic@gmail.com \\ ${ }^{4}$ Email: jaochoac2000@yahoo.com \\ ${ }^{5}$ Email: rickcwest@shaw.ca \\ 6Email:nferretti@conicet.gov.ar
}

\footnotetext{
${ }^{1}$ urn:1sid:zoobank.org:author:39EBE8FA-0842-4095-915E-7C26A1479456

${ }^{2}$ urn:1sid:zoobank.org:author:27BEB2DB-8514-42E6-B135-04B00C8213A6

${ }^{3}$ urn:1sid:zoobank.org:author:B3F1F751-E8A5-40F4-B579-0718A9A2EB17

${ }^{4}$ urn:1sid:zoobank.org:author:07A449F9-A323-4DB2-A112-2F71D8758196

${ }^{5}$ urn:1sid:zoobank.org:author:168C4C45-8203-4033-83BD-A337ED0AA2D0

${ }^{6}$ urn:lsid:zoobank.org:author:3A36F4C2-0EBD-48A7-BB4F-984AE0476581
}

\begin{abstract}
The spider genus Bistriopelma Kaderka, 2015 is endemic to Peru and includes three species known to date: Bistriopelma lamasi Kaderka, 2015, B. matuskai Kaderka, 2015 and B. titicaca Kaderka, 2017. The present contribution diagnoses, describes and illustrates two new species of Bistriopelma from Peru: B. peyoi sp. nov. and B. kiwicha sp. nov., both based on male and female. The male of B. peyoi sp. nov. is provided with a remarkable thoracic horn, and the species is the first horned tarantula for this genus. An updated distribution map for all known species is presented.
\end{abstract}

Keywords. South America, Mygalomorphae, Theraphosinae, taxonomy, distribution.

Nicoletta M., Chaparro J.C., Mamani L., Ochoa J.A., West R.C. \& Ferretti N.E. 2020. Two new endemic species of Bistriopelma (Araneae: Theraphosidae) from Peru, including a new remarkable horned tarantula. European Journal of Taxonomy 644: 1-20. https://doi.org/10.5852/ejt.2020.644 


\section{Introduction}

The family Theraphosidae Thorell, 1869, known as tarantulas, is the most speciose family among Mygalomorphae Pocock, 1892 and currently contains more than 900 described species according to the World Spider Catalog (2019). They are the largest and heaviest spiders of the world inhabiting almost all terrestrial ecosystems, with the exception of polar areas. The highest abundance and diversity are registered for tropical, subtropical, semi-arid and arid regions. They can be found from sea level to about 4500 meters a.s.l. and some can be found living deep inside caves. Inside this family, eleven subfamilies are recognized, Theraphosinae Thorell, 1870 being the most diverse, with more than 60 genera (World Spider Catalog 2019). This monophyletic group is characterized by the presence of urticating setae of type III, a male palpal bulb with the subtegulum extended over the tegulum, the embolus with keels, and the presence of tarsal clavate trichobothria in a straight row (Pérez-Miles et al. 1996; Guadanucci 2014).

The genus Bistriopelma Kaderka, 2015 belongs to the subfamily Theraphosinae. Its representatives are characterized by the presence of two abdominal dorsolateral patches of the type III urticating setae. Females are recognized by the spermathecae composed of two subparallel receptacula terminated with transverse oval lobes. Males are characterized by the aspect of the bulb, with a long and sigmoid curved embolus provided with two prolateral keels (prolateral superior and inferior) (Kaderka 2015). Bistriopelma was originally established by Kaderka (2015) with two species from the Andean region in Peru. In this work, Bistriopelma lamasi Kaderka, 2015 was described as the type species of the genus, based on male and female from Ayacucho, Peru. Bistriopelma matuskai Kaderka, 2015 was described from Apurimac, Peru, based only on females. Later, Kaderka (2017) described the male of B. matuskai and the new species, B. titicaca Kaderka, 2017, from Puno, Pucará, based on both sexes.

During examination of material deposited at the Museo de Biodiversidad del Perú, two new species of Bistriopelma were discovered and are, herein, described and illustrated. One of them includes a new remarkable horned tarantula that now represents the record of another theraphosid genus with this rare morphological feature.

\section{Material and methods}

The material examined in the present study is deposited in the Museo de Biodiversidad del Perú, Cusco, Peru (MUBI), Curator José A. Ochoa.

All measurements are in millimeters. Total length was taken from the dorsal view and does not include the chelicera and spinnerets. Carapace length was measured from the clypeus margin to the posterior margin. Palp and leg segments were measured between the joints in dorsal view: femur, patella, tibia, metatarsus and tarsus. The length and width of the carapace, eye tubercle, labium and sternum are the maximum values obtained. Legs measurements were taken with a digital caliper to the nearest $0.001 \mathrm{~mm}$ and other measurements and photographs were obtained with a Zeiss Stemi 305 stereo microscope, Zeiss AxioCam, and ZEN Imaging software ver. 1.0. Terminology for tibial apophyses (or spurs) follows the general usage in Theraphosidae and it includes the two branches (e.g., Bertani 2001; Pérez-Miles et al. 2008). Male palpal bulb keel terminology follows Bertani (2000). The extent of tarsal and metatarsal scopulae on ventral side of both leg segments was expressed as a proportion of the total length of segment, from apical end. The leg spination was described for each leg segment into the four quadrants (ventral, prolateral, retrolateral and dorsal) and each quadrant described separately from basal to apical section (modified from Petrunkevitch 1925; Kaderka 2015, 2017). Urticating setae terminology follows Cooke et al. (1972) and Bertani \& Guadanucci (2013). 


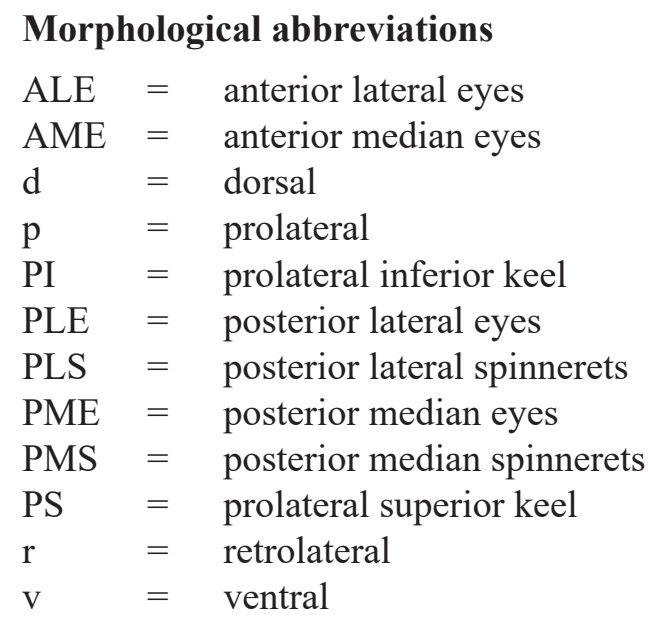

\section{Results}

Order Araneae Clerck, 1757

Infraorder Mygalomorphae Pocock, 1892

Family Theraphosidae Thorell, 1869

Subfamily Theraphosinae Thorell, 1870

Genus Bistriopelma Kaderka, 2015

\section{Material examined}

Bistriopelma titicaca Kaderka, 2017

PERU • 1 q; Puno, Lampa, Muruhuanca; 15²1'30.48" S, 70²2'40.87" W; 3900 m a.s.1.; 9 Aug. 2017; J.C.Chaparro and G. Herrera leg.; MUBI 57.

Bistriopelma peyoi sp. nov. urn:lsid:zoobank.org:act:9A64CE8C-D0A4-4100-A6E6-CC8C34BFC987

Figs $1-7,14$

\section{Diagnosis}

Males of $B$. peyoi sp. nov. can be distinguished from the other known species of Bistriopelma by a large projection of the cephalic region over a procurved fovea (Figs 1,2A-B) and by the tegulum of the palpal bulb with a short triangular basal projection (domed in the other known species) (Fig. 4A-B). Females resemble B. matuskai in the absence of fovea (Figs 5A-B, 6A-B) (present in B. lamasi, B. titicaca and $B$. kiwicha sp. nov.) and the undeveloped basal tubercles covered with maxillary cuspules (Fig. 6E) (developed in B. lamasi, B. titicaca and B. kiwicha sp. nov.), but differ by the color pattern with a patch of red hairs in the anterior dorsal abdomen (absent in B. matuskai, Kaderka 2015: fig. 21), the yellowish hairs on carapace margins and cephalic area (a small patch of rose hairs are present in cephalic area of B. matuskai, Kaderka 2015: fig. 21) and by the long red hairs on ventral coxae, trochanter and femora (absent in B. matuskai, Kaderka 2015: fig. 21) (Fig. 5A-B), and by the presence of a posterior band of dark pubescence in maxillae (Fig. 6D-E). In addition, females can be distinguished from the other known species by the spermathecal receptacles with large granules pointing outwards (Fig. 7).

\section{Etymology}

The specific epithet is a patronym in honor of the Belgian cartoonist Pierre Culliford (1928-1992), mostly known by his pseudonym 'Peyo', who created the comic strip 'The Smurfs'. The type locality of this new species is located near the Pampachiri Stone Forest, which is known as Smurf's house because 
of the conical rock formations. Moreover, the prominent projection of the cephalic region of the male resembles the shape of the Smurfs' hats.

\section{Material examined}

\section{Holotype}

PERU • O’; Apurimac, Aymaraes, Tapairihua, Ayamachay; $14^{\circ} 15^{\prime} 45.00^{\prime \prime} \mathrm{S}, 73^{\circ} 28^{\prime} 7.71^{\prime \prime} \mathrm{W} ; 3861 \mathrm{~m}$ a.s.1.; 9 Dec. 2018; J.C. Chaparro, L. Mamani leg.; MUBI 73.

\section{Paratypes}

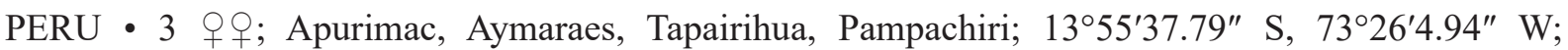
4027 m a.s.1.; 8 Dec. 2018; J.C. Chaparro, L. Mamani leg.; MUBI 70.

\section{Description}

Male (holotype, MUBI 73)

COLORATION. Live specimens: Carapace dark covered with long yellow setae giving a 'golden' aspect; abdomen black dorsally covered with long red hairs mainly on proximal region and on patches of urticating setae; spinnerets black; legs dark with pale yellow hairs mainly on femora, patellae and tibiae (Fig. 1). In ethanol: carapace reddish brown covered with long yellow setae giving a 'golden' aspect mainly on cephalic region, central thoracic region and carapace margins; abdomen black covered with long pale setae and patch of long yellow setae on dorsal apical region with two dorsolateral patches of urticating setae, ventrally black with book lung markings and region above epigastric furrow light brown, spinnerets black; legs brown covered with pale setae, labium and maxillae yellowish brown, sternum brown (Fig. 2).
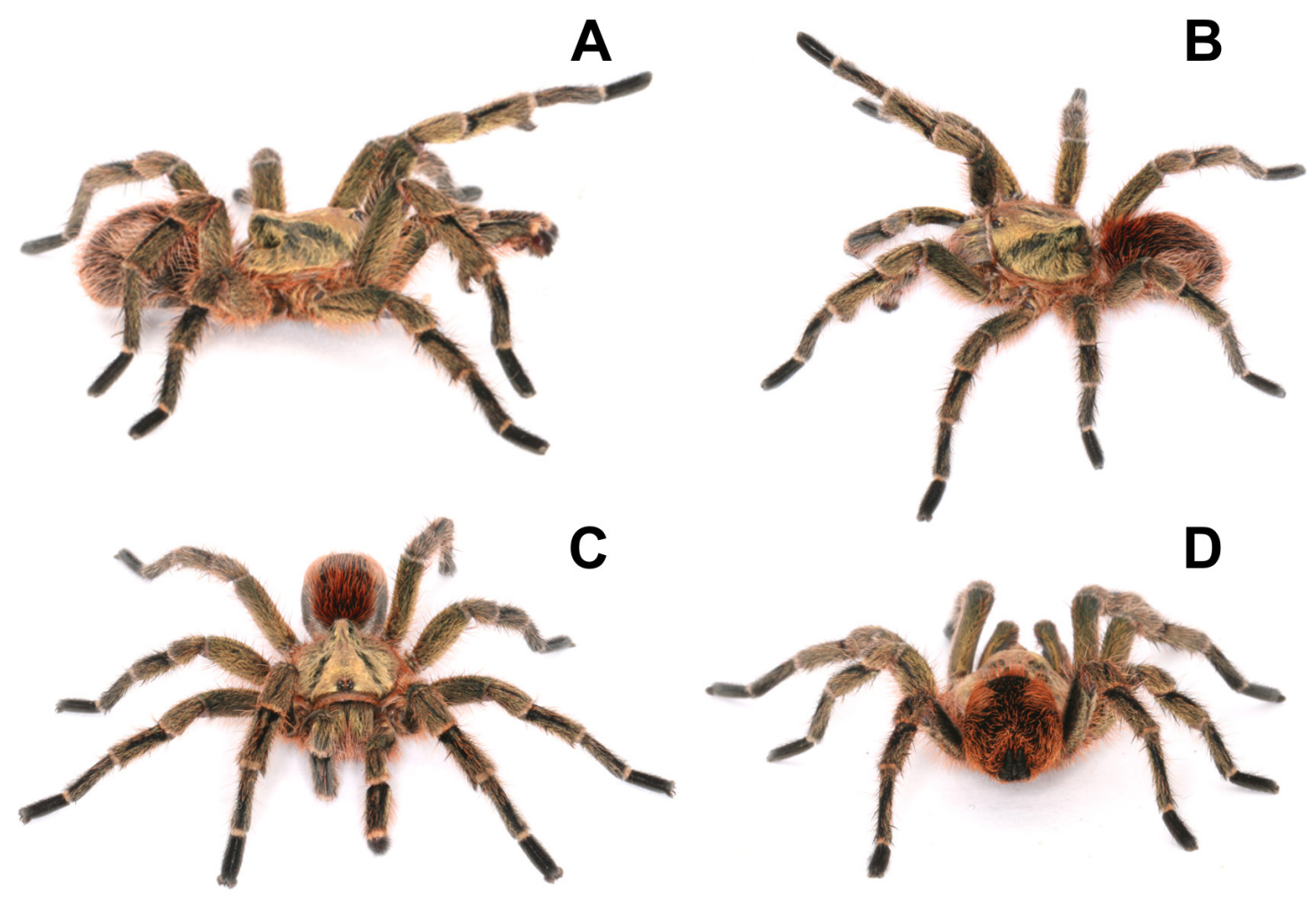

Fig. 1. Bistriopelma peyoi sp. nov., holotype, đ̊ (MUBI 73). A-D. Habitus. Photos: Juan C. Chaparro. 
Table 1. Bistriopelma peyoi sp. nov., holotype, $\widehat{\partial}$ (MUBI 73); length of palpal and leg segments.

\begin{tabular}{lccccc}
\hline & Leg I & Leg II & Leg III & Leg IV & Palp \\
\hline Femur & 7.72 & 6.99 & 6.09 & 7.37 & 5.37 \\
Patellae & 4.12 & 3.61 & 2.77 & 3.90 & 3.35 \\
Tibiae & 5.11 & 4.51 & 3.36 & 5.22 & 4.72 \\
Metatarsus & 5.78 & 5.06 & 4.56 & 5.96 & - \\
Tarsus & 4.04 & 3.58 & 3.05 & 3.46 & 1.85 \\
Total & 27.16 & 23.63 & 19.26 & 25.40 & 13.97 \\
\hline
\end{tabular}

Measurements. Total length, without chelicerae and spinnerets: 18.89. Carapace: length 8.87 , width 8.59. Abdomen: length 9.22. Eye tubercle: length 1.19, width 1.52. Eyes sizes and interdistances: AME 0.17, ALE 0.38, PME 0.16, PLE 0.39, AME-AME 0.37, AME-ALE 0.16, PME-PME 0.70, PME-PLE 0.09, ALE-PLE 0.21. Labium: length 1.46, width 1.25. Sternum: length 4.09, width 3.91. Length of legs and palpal segments in Table 1.

Cephalothorax. Cephalic region with prominent projection over procurved fovea (Fig. 2A-B). Clypeus very narrow. Anterior eye row procurved and posterior eye row recurved (Fig. 2H). Labium with 7 cuspules (Fig. 2G). Maxillae with 78-91 (right/left) cuspules (Fig. 2F-G). Apical half of maxillae ventrally covered with short spiniform setae. Sternal sigillae small and narrow, located near coxa III (elongated), II and I (oval). All sigillae distant about 2 diameters from margin. Chelicerae with 9 welldeveloped teeth on promargin of furrow and absence of tooth on retromargin.
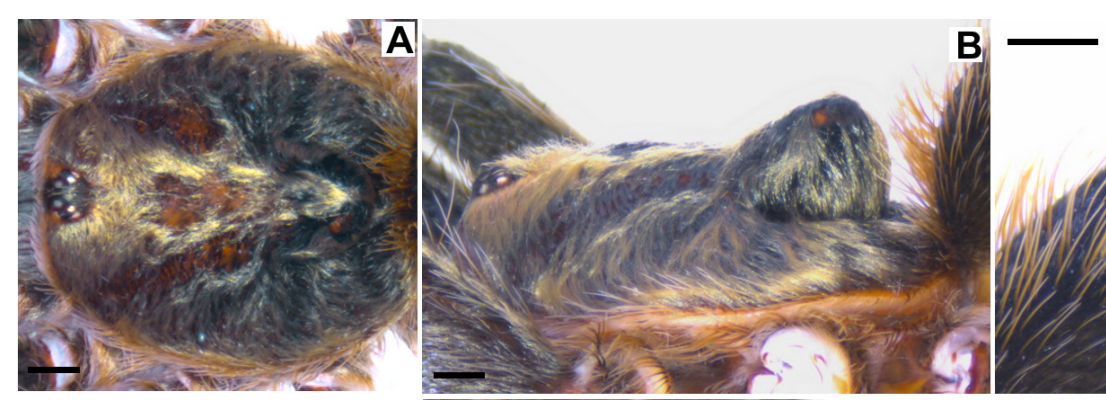

C
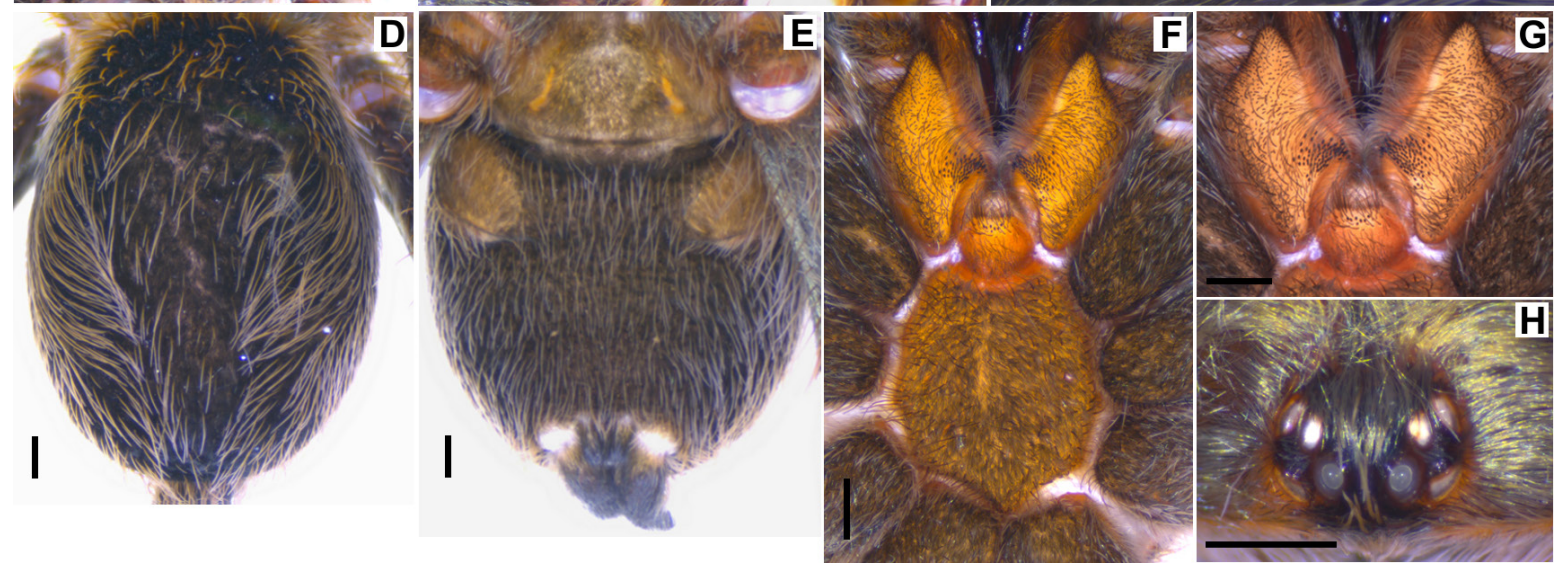

Fig. 2. Bistriopelma peyoi sp. nov., holotype, $\widehat{\jmath}$ (MUBI 73). A. Carapace, dorsal view. B. Carapace, lateral view. C. Urticating setae patch. D. Abdomen, dorsal view. F. Abdomen, ventral view. F. Sternum, labium and maxillae, ventral view. G. Labium and maxillae, ventral view. H. Eyes. Scale bars: A-B, $\mathrm{D}-\mathrm{E}=5 \mathrm{~mm} ; \mathrm{C}, \mathrm{F}-\mathrm{H}=1 \mathrm{~mm}$. 

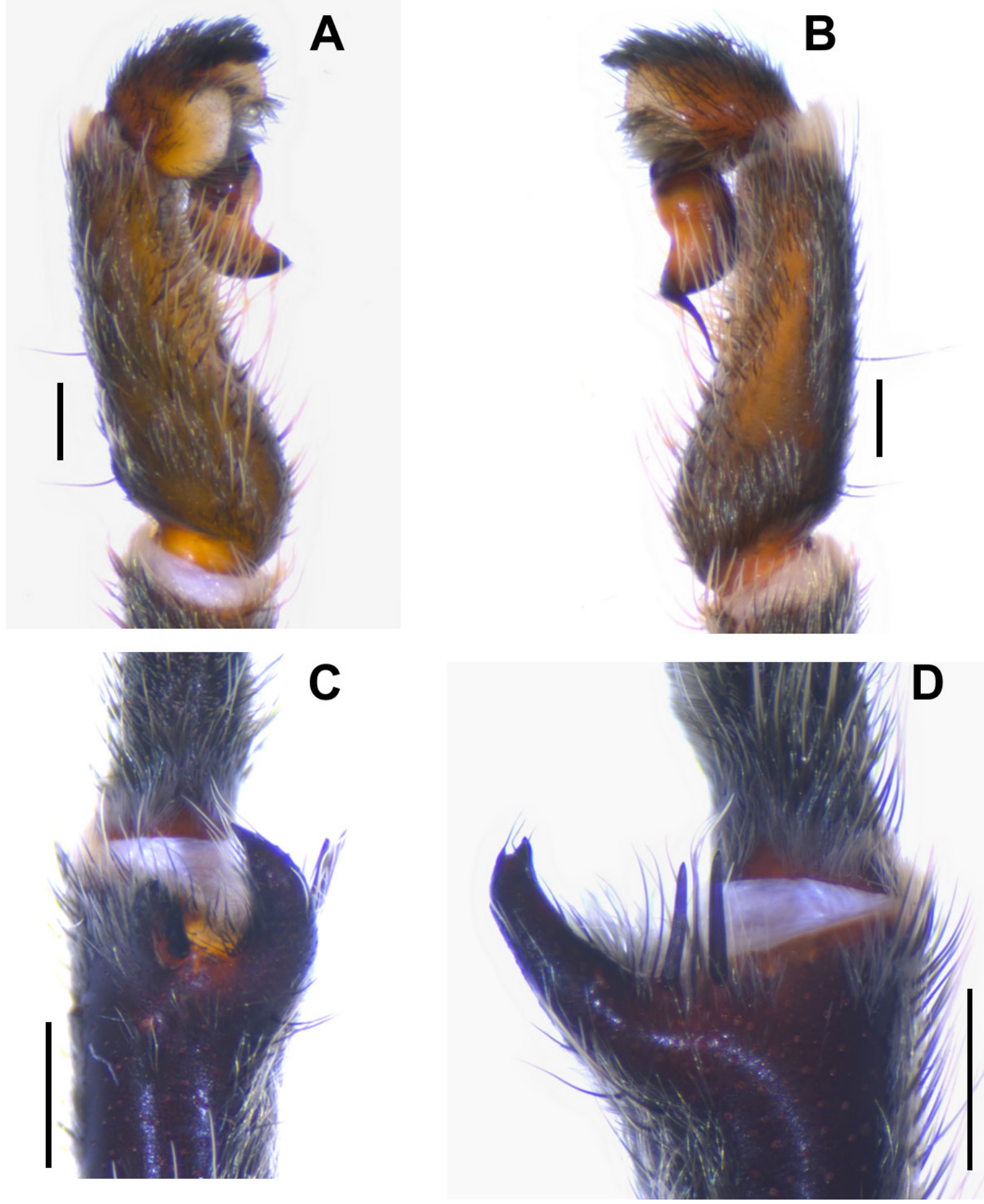

Fig. 3. Bistriopelma peyoi sp. nov., holotype, ô (MUBI 73). A-B. Cymbium, tibia and patella. A. Retrolateral view. B. Prolateral view. - C-D. Tibial apophysis. C. Ventral view. D. Prolateral view. Scale bars $=1 \mathrm{~mm}$. 
AвDOMEN. Urticating setae: Type III located in two dorsolateral patches with elongated golden setae (Fig. 2C). Spinnerets: PMS, 0.74 long; PLS, three-segmented, 3.15 long.

LEGS AND PALPS. Leg formula: I > IV > II > III. All paired tarsal claws with 3-4 ventral teeth on each. Scopulae: Ventrally all tarsi fully scopulated. Tarsi I and II entire, III and IV divided by band of setae. Metatarsus I 1/3 scopulated, II $1 / 2$ scopulated, III 1/2 scopulated, IV 1/3 scopulated. Dorsal face of all tarsi with two longitudinal rows of claviform trichobothria. Tibia I two-branched tibial apophysis: ventral branch with single strong apical spine and prolateral branch with single inner strong spine, of same length as branch (Fig. 3C-D). Metatarsus I contacts apex of ventral branch of tibial apophysis when flexed (Fig. 3C). Palps with cymbial lobes almost equal in sizes covered with long setae (Fig. 3A-B). Tibia tapering to the apex.

SPINATION. Femora, patellae and tarsi of legs I-IV and palps 0. Tibiae: palp 0; legs: I 2r (apical), 1-1p, 1-1-1v; II 1-1-1-1-2-4v; III 1r (apical), 1-1p, 1-1v; IV 1r (apical), 1-1-2v. Metatarsi: I 1v (apical); II 1-1d, 1p (basal), 1-2v; III 1-1d, 1-1r, 1-1-1-1-2p, 1-2v; IV 1-1r, 1-1-1-1-1-2p, 1-2v.

PALPAL BULB. Bulb with narrow embolus projecting retrolaterally from tegulum, sigmoidly curved, and two close subparallel smooth keels, PS and PI (Fig. 4A-B). Tegulum with short triangular basal projection (Fig. 4A).

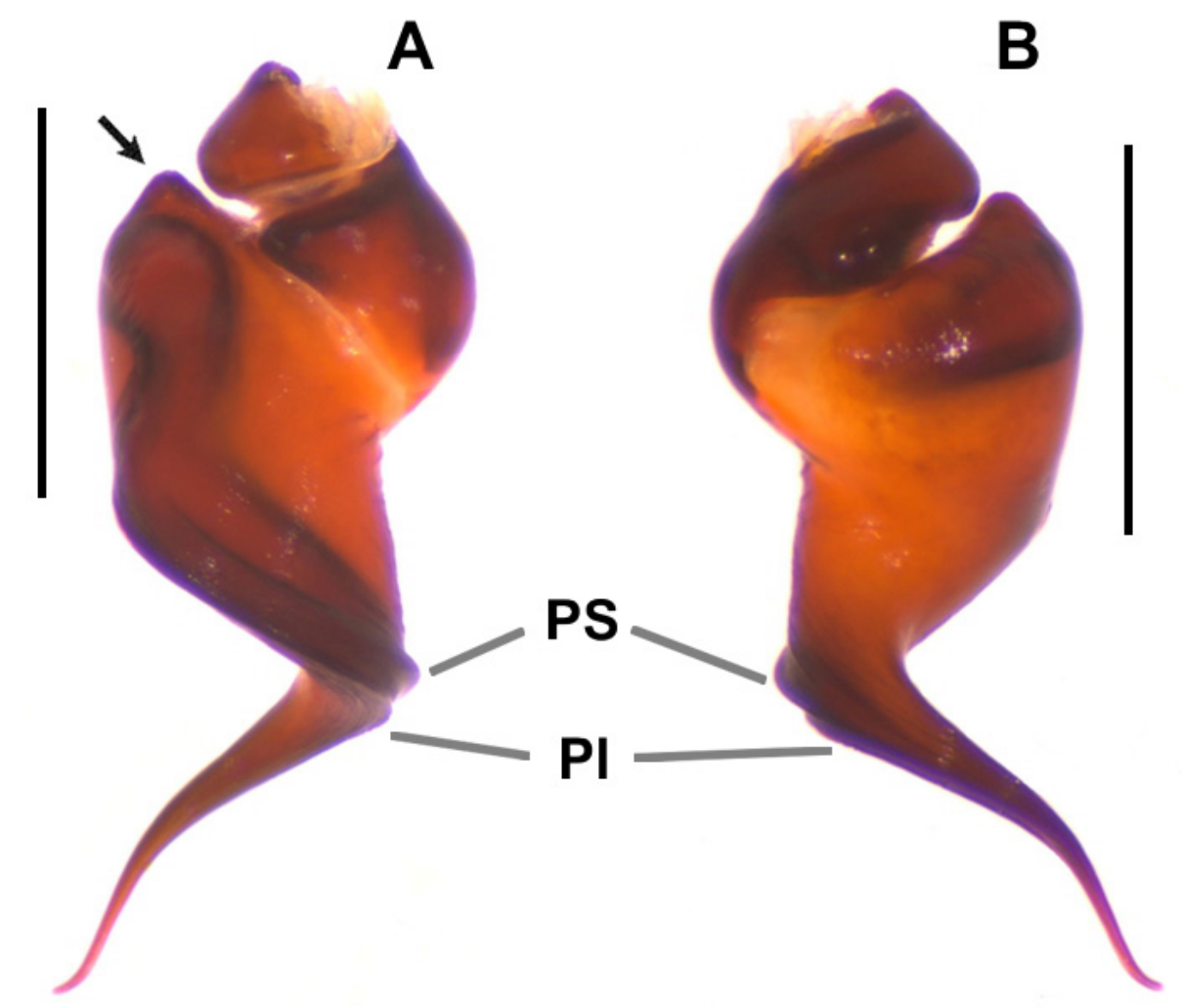

Fig. 4. Palpal bulb of Bistriopelma peyoi sp. nov., holotype, § (MUBI 73). A. Prolateral view (arrow indicates the basal triangular projection on tegulum). B. Retrolateral view. Scale bars $=1 \mathrm{~mm}$. 
Table 2. Bistriopelma peyoi sp. nov., paratype, $q$ (MUBI 70); length of palpal and leg segments.

\begin{tabular}{lccccc}
\hline & Leg I & Leg II & Leg III & Leg IV & Palp \\
\hline Femur & 7.75 & 6.78 & 5.10 & 6.85 & 5.33 \\
Patellae & 4.54 & 3.97 & 3.18 & 3.80 & 3.33 \\
Tibiae & 5.19 & 3.66 & 2.86 & 4.12 & 3.62 \\
Metatarsus & 3.77 & 3.40 & 3.24 & 4.63 & - \\
Tarsus & 2.97 & 2.89 & 2.79 & 2.97 & 3.16 \\
Total & 23.44 & 20.80 & 17.89 & 22.12 & 14.55 \\
\hline
\end{tabular}

Female (paratype, MUBI 70)

Coloration. Live specimen: Carapace dark covered with long yellow setae giving a 'golden' aspect mainly on cephalic region and margins; abdomen black dorsally covered with long red hairs mainly on proximal region and on patches of urticating setae; spinnerets black; legs dark with reddish hairs mainly ventrally on femora, patellae and tibiae (Fig. 5A-B). In ethanol: Carapace brown covered with long yellow setae giving a 'golden' aspect mainly on cephalic region and carapace margins; abdomen black covered with long pale setae and patch of long yellow setae on dorsal apical region with two dorsolateral patches of urticating setae, spinnerets black; legs and sternum ventrally dark brown; labium and maxillae reddish brown (Fig. 6).

Measurements. Total length, without chelicerae and spinnerets: 26.21. Carapace: length 9.27, width 8.30. Abdomen: length 12.92. Clypeus: 0.38. Eye tubercle: length 0.91, width 1.42. Eyes sizes and interdistances: AME 0.15, ALE 0.33, PME 0.16, PLE 0.36, AME-AME 0.32, AME-ALE 0.21, PMEPME 0.63, PME-PLE 0.06, ALE-PLE 0.23. Labium: length 1.36, width 1.91. Sternum: length 4.77, width 4.63. Length of legs and palpal segments in Table 2.

Cephalothorax. Carapace without fovea and cephalic region raised (Fig. 6A-B). Anterior eye row slightly procurved and posterior eye row recurved (Fig. 6F). Labium with 11 cuspules (Fig. 6E). Maxillae with 99-105 (right/left) cuspules (Fig. 6E). Apical half of maxillae ventrally covered with short spiniform setae and dark pubescence on basal ventral maxillae (Fig. 6D-E). Sternal sigillae small and narrow, located near coxa III (elongated), II and I (oval). All sigillae distant about 2 diameters from margin. Chelicerae with 8 well-developed teeth on promargin of furrow and 1 very small tooth on retromargin.

ABDomen. Urticating setae: Type III located in two dorsolateral patches with elongated golden setae (Fig. 6C). Spinnerets: PMS, 0.96 long; PLS, three-segmented, 3.61 long.

LEGS AND PALPS. Leg formula: I > IV > II > III. All paired tarsal claws with 3-4 ventral teeth on each. Scopulae: Ventrally all tarsi fully scopulated and not divided. Metatarsi I fully scopulated, II $2 / 3$ scopulated, III $2 / 3$ scopulated, IV $1 / 2$ scopulated. Dorsal face of all tarsi with two longitudinal rows of claviform trichobothria.

SPINATION. Femora, patellae and tarsi of legs I-IV and palps 0. Tibiae: palp 2v (apical); legs I-IV 0. Metatarsi: I 1v (apical); II 2v (apical); III 1-1r, 1p; IV 1-1r, 1p (apical), 3v (apical).

SPermatheCA. Two separated seminal receptacles with large granules, each distally ended with oval lobe pointing outwards without ventral projections (Fig. 7). 

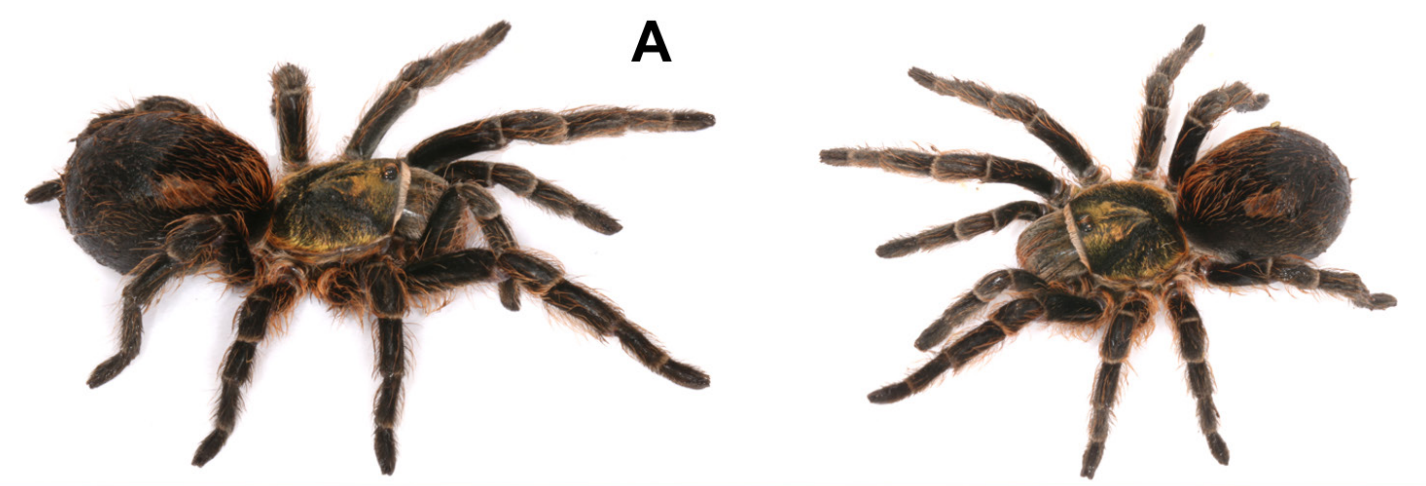

B

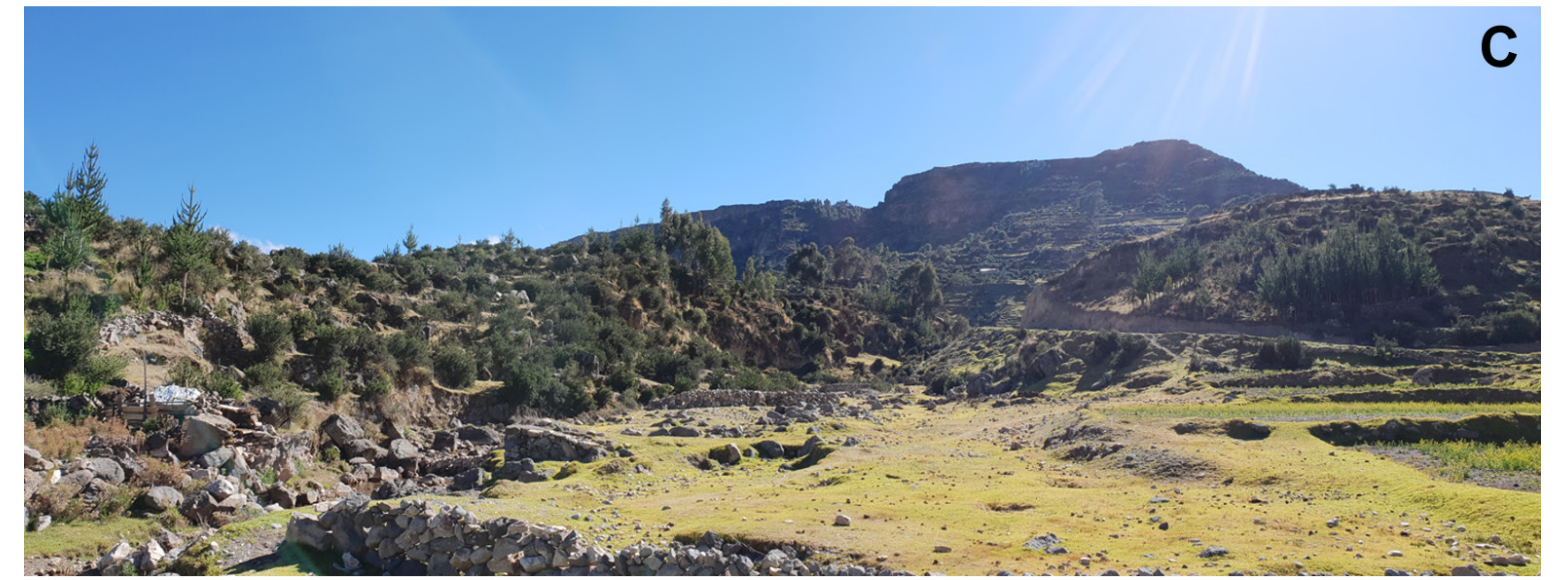

Fig. 5. Bistriopelma peyoi sp. nov., paratype, $\varnothing$ (MUBI 70). A-B. Habitus. C. Habitat at type locality. Photos: Juan C. Chaparro.

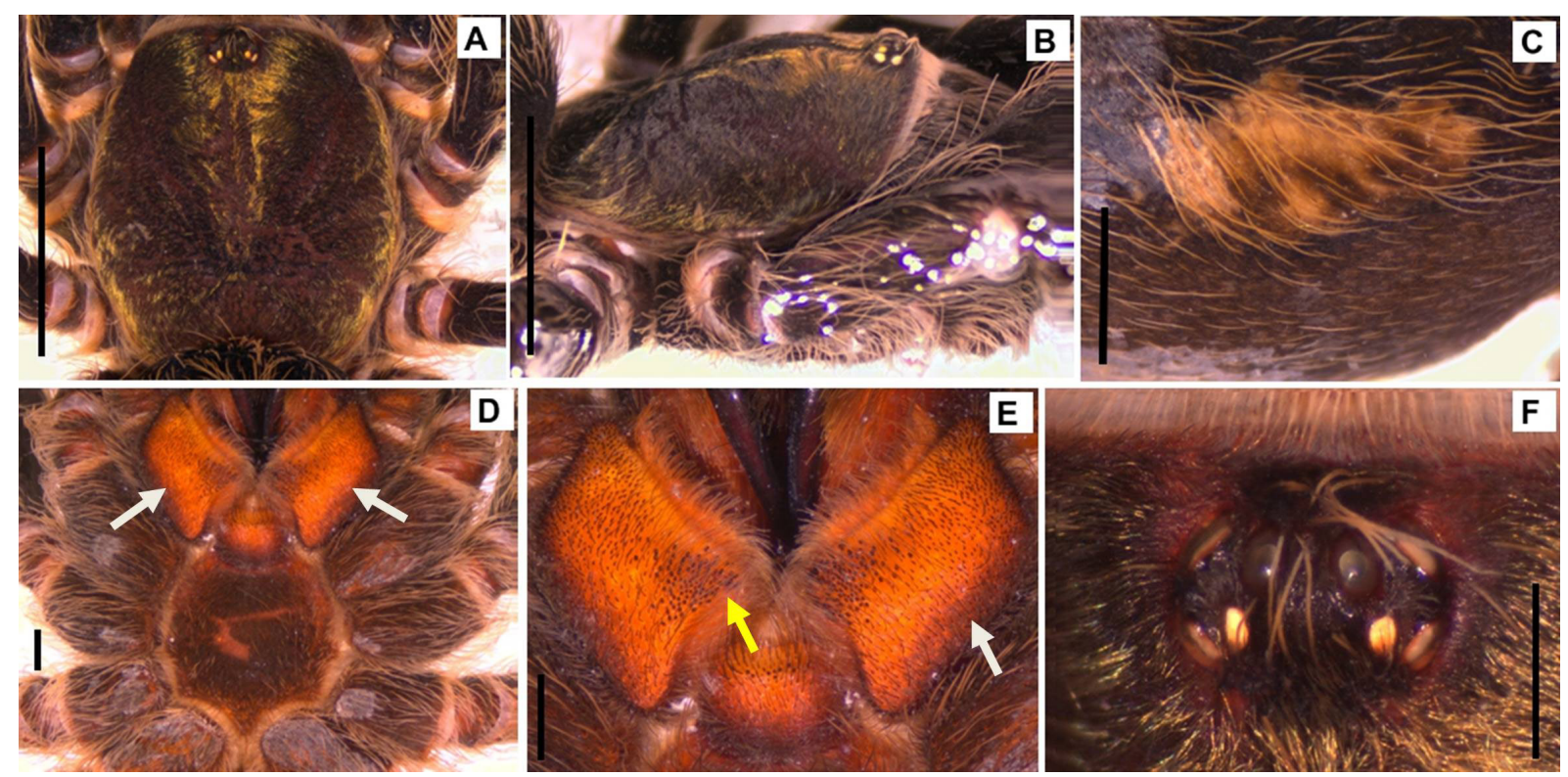

Fig. 6. Bistriopelma peyoi sp. nov., paratype, $q$ (MUBI 70). A. Carapace, dorsal view. B. Carapace, lateral view. C. Urticating setae patch. D. Sternum, labium and maxillae, ventral view, white arrows indicate the dark pubescence in the basal maxillae. E. Labium and maxillae, ventral view (the yellow arrow indicates the basal tubercle with cuspules well developed and the white arrow indicates the dark pubescence in the basal maxillae). F. Eyes. Scale bars: A-B $=5 \mathrm{~mm} ; \mathrm{C}-\mathrm{F}=1 \mathrm{~mm}$. 


\section{Distribution and natural history}

Bistriopelma peyoi sp. nov. is known from Pampachiri and Ayamachai (Figs 5C, 14), Department Apurimac, Peru, at elevations from 3861 to $4027 \mathrm{~m}$ a.s.1, and both are separated by $37 \mathrm{~km}$ in a straight line. Specimens were collected during the rainy season (December), under rocks, between bushes and rocky areas (Fig. 5C). This species inhabits high Andean puna, where most of the area was covered by pasturelands and introduced pine trees. Throughout the area we could find small villages, farming, and grazing activities of cows and sheep.

\section{Bistriopelma kiwicha sp. nov. \\ urn:1sid:zoobank.org:act:059B96EB-D154-4F66-969A-168E800E5A70}

Figs 8-14

\section{Diagnosis}

Males of Bistriopelma kiwicha sp. nov. differ from B. peyoi sp. nov. in the absence of a projection on cephalic region (Fig. 8A) and by the domed basal projection on tegulum (Fig. 10A). Males also differ from B. matuskai in the presence of a fovea (Fig. 8A) and from B. titicaca and B. lamasi in the absence of spiniform setae on cymbium and almost equal size of cymbial lobes (Fig. 9A-B) (unequal in B. titicaca and B. lamasi). Females of B. kiwicha sp. nov. are distinguished from B. peyoi sp. nov. and B. matuskai by the presence of a fovea (Fig. 12A-B). Also, females of B. kiwicha sp. nov. differ from B. titicaca and B. lamasi by the procurved fovea (Fig. 12A) (straight in B. titicaca and B. lamasi). Also, females

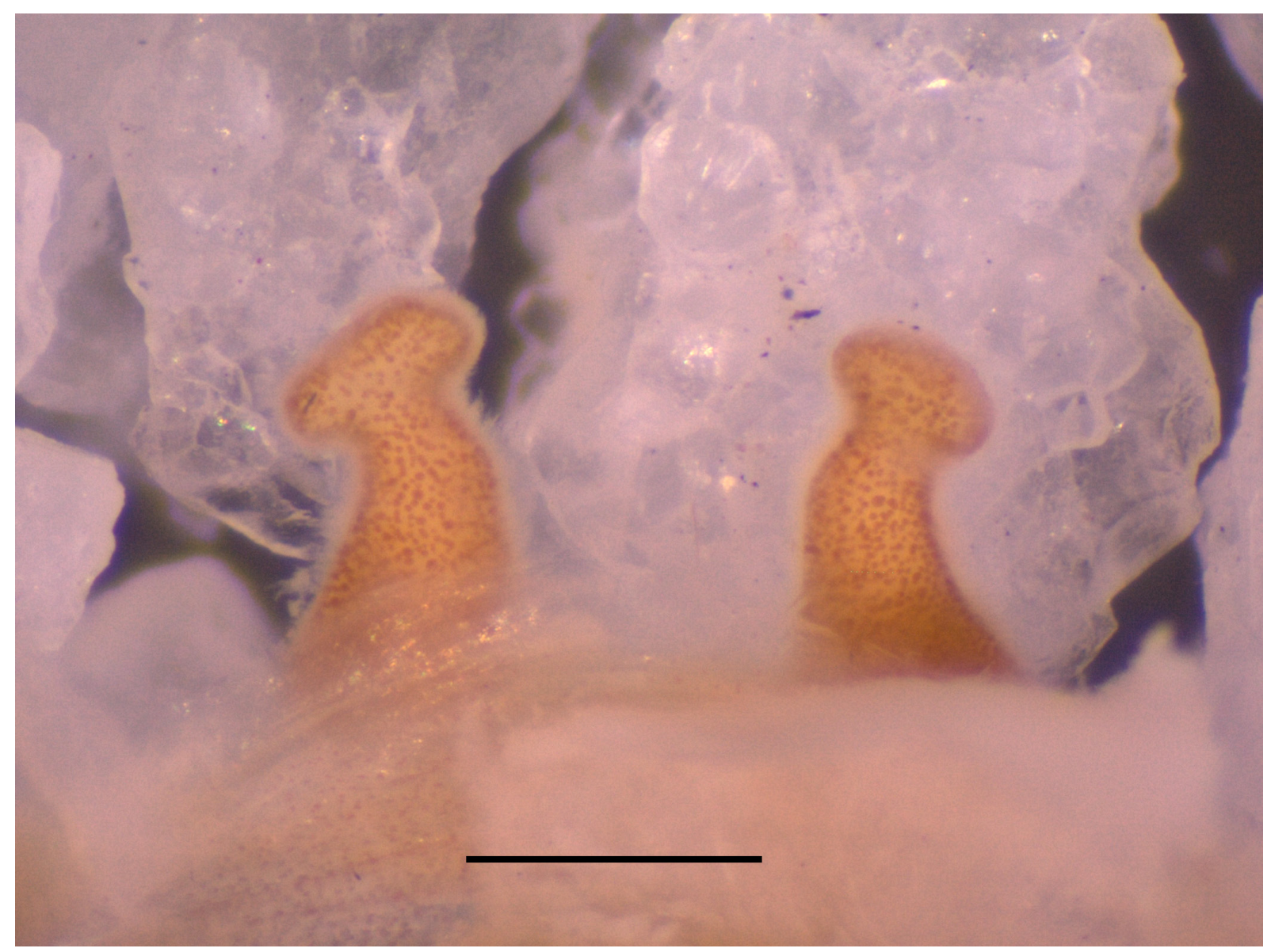

Fig. 7. Bistriopelma peyoi sp. nov., paratype, $q$ (MUBI 70); spermathecae, dorsal view. Scale bar $=$ $1 \mathrm{~mm}$. 
differ from B. lamasi by the absence of a dark pubescence on ventral maxillae (Fig. 12F-G) and from B. titicaca by the absence of spiniform setae on prolateral faces of coxae I-IV (Fig. 12F). In addition, the two fine-grained separated seminal receptacles of B. kiwicha sp. nov. resemble those of B. matuskai and $B$. titicaca, but differ from them by the shorter ducts and absence of ventral projections (Fig. 13).

\section{Etymology}

The specific epithet, kiwicha, is a Quechua word referring to Amaranthus caudatus L., a plant widely cultivated in the Peruvian Andes, particularly in the district of San Salvador, where this new species was found. It has been used in the form of cereals or flour from the plant's seeds for more than 1400 years and was included in the daily diet during the Inca civilization.

\section{Material examined}

\section{Holotype}

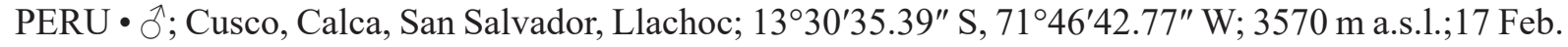
2006; J.A. Ochoa leg.; MUBI 12.

\section{Paratype}

PERU • 1 9; Cusco, Paucartambo, Highway 26, road to Manu province; $13^{\circ} 28^{\prime} 33.35^{\prime \prime}$ S, $71^{\circ} 39^{\prime} 25.92^{\prime \prime}$ W; 3903 m a.s.1.; 6 Oct. 2017; R. West, J. Richards leg.; MUBI 41.
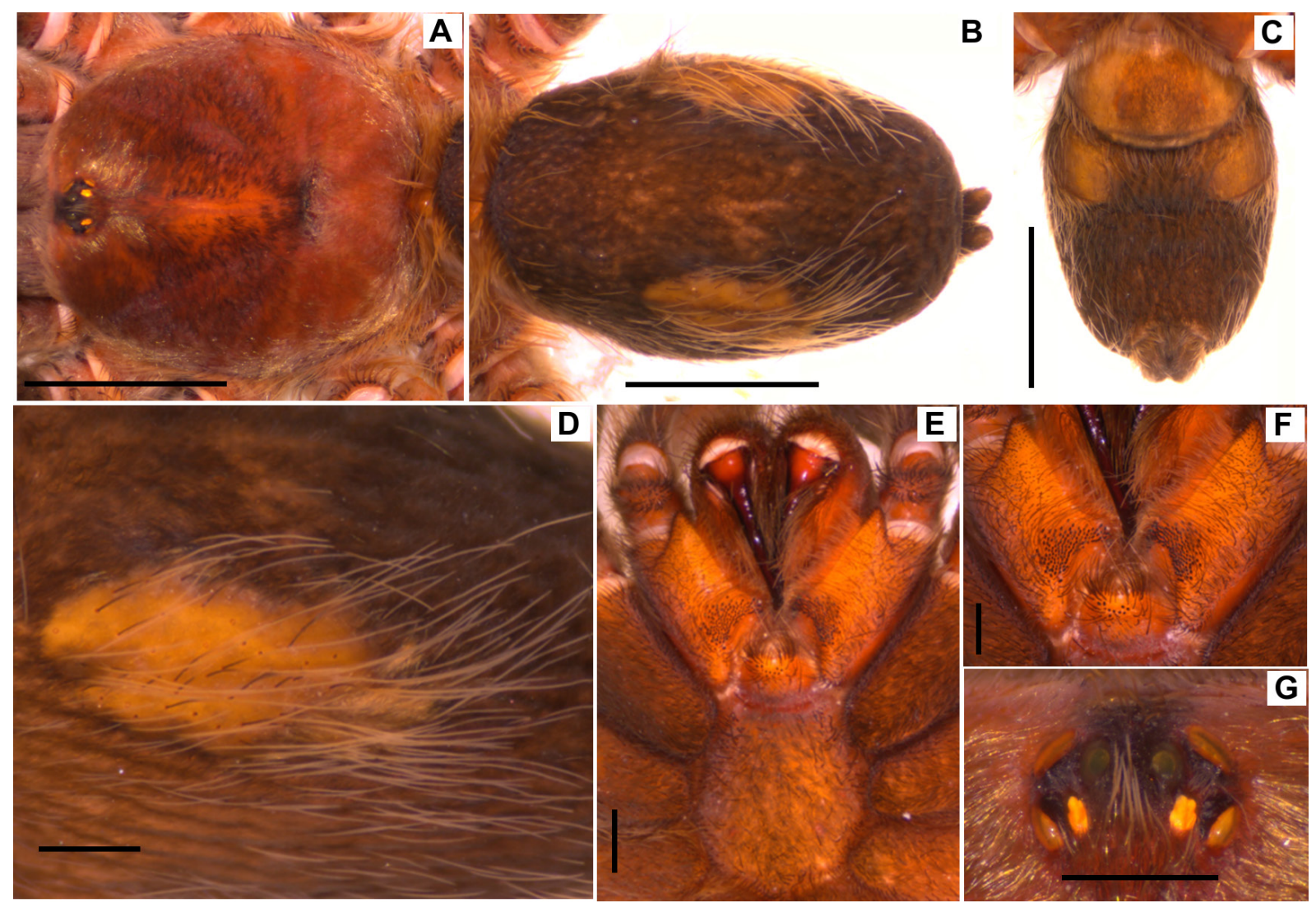

Fig. 8. Bistriopelma kiwicha sp. nov., holotype, $\widehat{\jmath}$ (MUBI 12). A. Carapace, dorsal view. B. Abdomen, dorsal view. C. Abdomen, ventral view. D. Urticating setae patch. E. Sternum, labium and maxillae, ventral view. F. Labium and maxillae, ventral view. G. Eyes. Scale bars: A-C $=5 \mathrm{~mm}$; D-G $=1 \mathrm{~mm}$. 

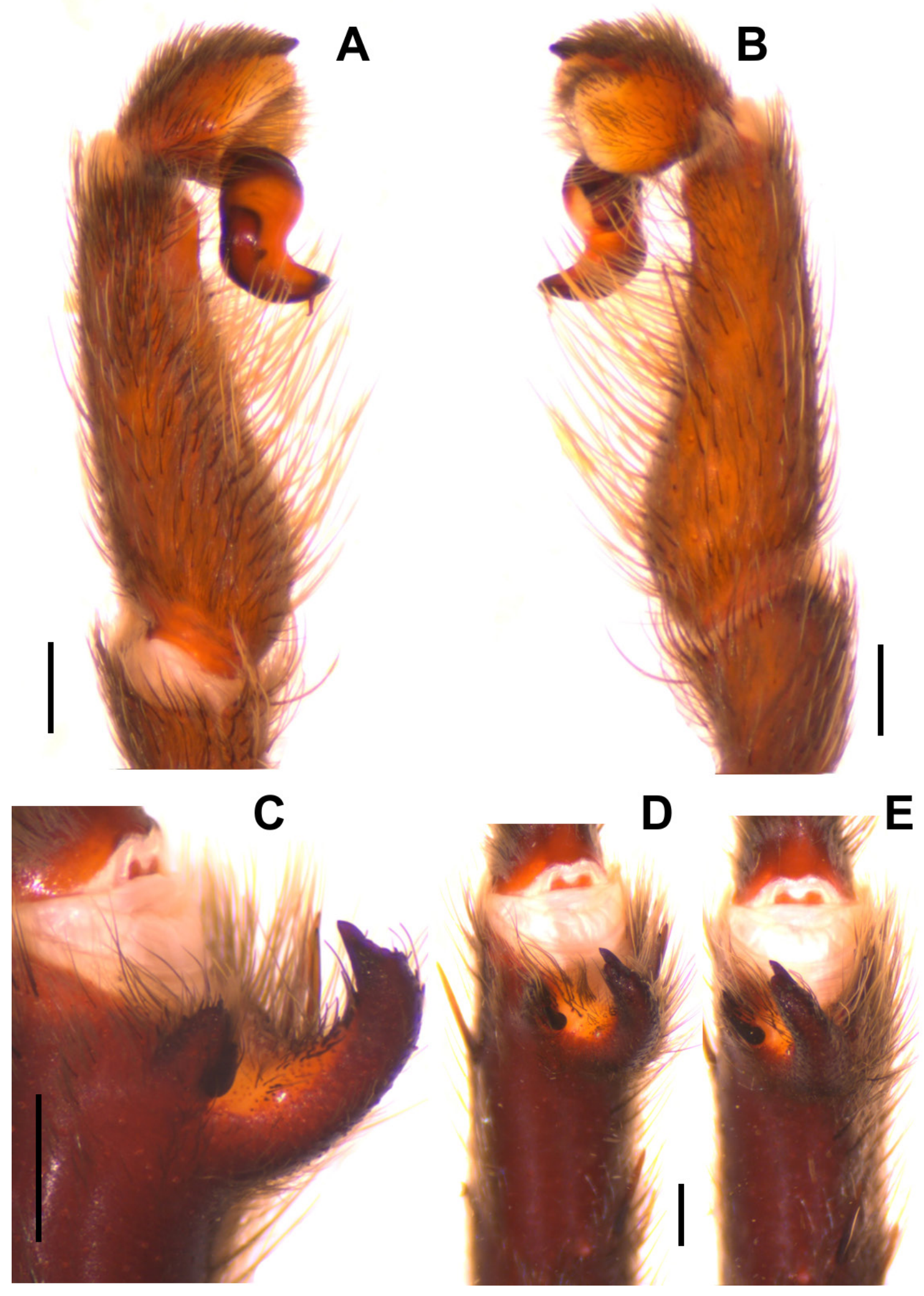

Fig. 9. Bistriopelma kiwicha sp. nov., holotype, ô (MUBI 12). A-B. Cymbium, tibia and patella. A. Prolateral view. B. Retrolateral view. - C-E.Tibial apophysis. D. Retrolateral view (detail of branches). D. Retrolateral view. E. Ventral view. Scale bars $=1 \mathrm{~mm}$. 


\section{Description}

Male (holotype, MUBI 12)

COLORATION. In ethanol: Carapace reddish brown with dark short setae on cephalic region between the fovea and eyes covered with yellow setae around eye tubercle and carapace margins; abdomen black with two patches of long yellow setae on dorsal apical region on dorsolateral patches of urticating setae, ventrally dark brown with book lung markings and region above epigastric furrow light brown, spinnerets brown; legs brown, labium and maxillae yellowish brown, sternum brown (Fig. 8).

MEASUREmEnTs. Total length, without chelicerae and spinnerets: 21.52. Carapace: length 9.38, width 8.47. Abdomen: length 9.36. Eye tubercle: length 1.41, width 1.50. Eyes sizes and interdistances: AME 0.17, ALE 0.51, PME 0.20, PLE 0.40, AME-AME 0.32, AME-ALE 0.21, PME-PME 0.61, PME-PLE 0.10, ALE-PLE 0.17. Labium: length 1.26, width 1.72. Sternum: length 4.49, width 3.64. Length of legs and palpal segments in Table 3 .

Cephalothorax. Fovea slightly procurved (Fig. 8A). Clypeus very narrow. Anterior eye row slightly procurved and posterior eye row recurved (Fig. 8G). Labium with 10 cuspules (Fig. 8F). Maxillae with 140-139 (right/left) cuspules (Fig. 8F). Apical half of maxillae ventrally covered with short spiniform

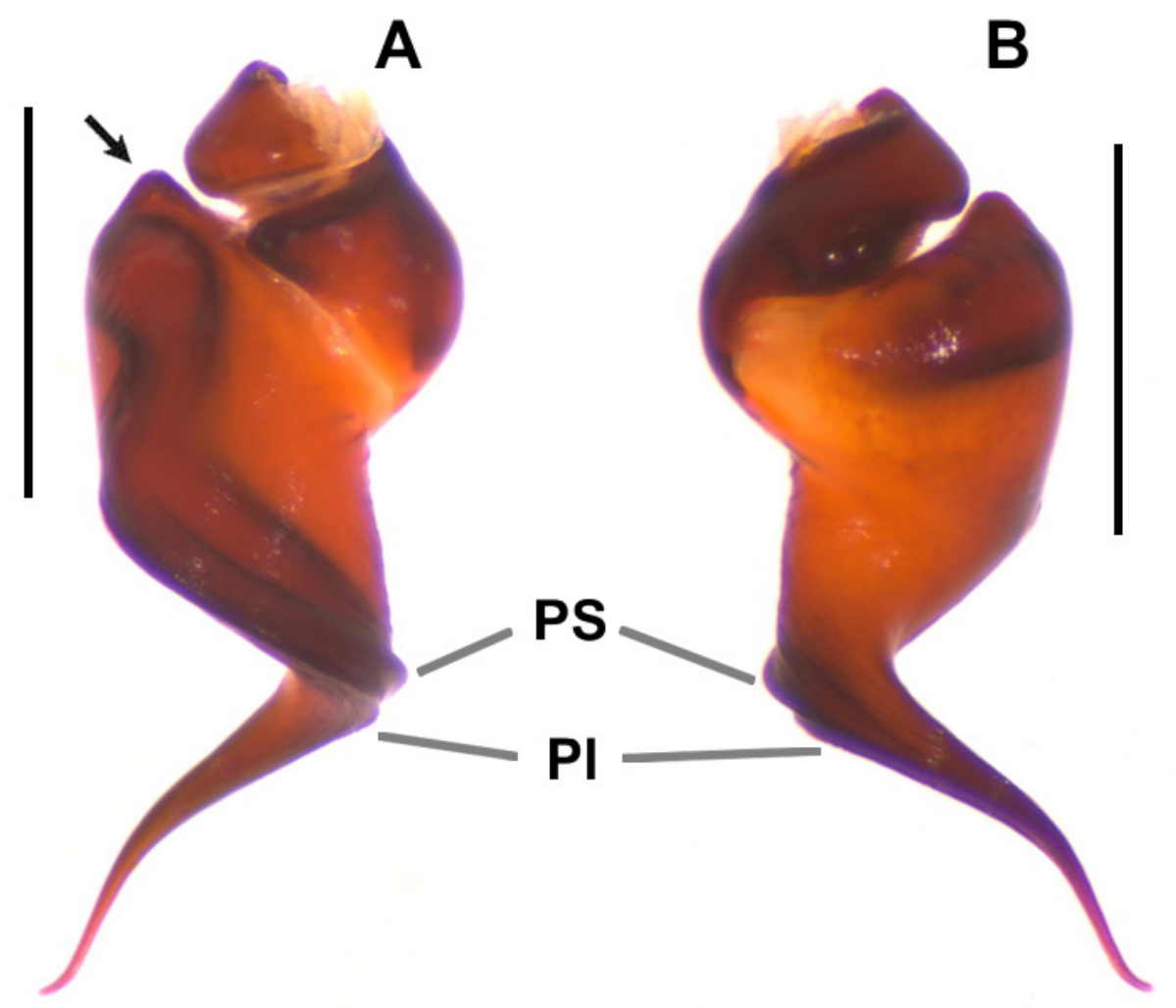

Fig. 10. Palpal bulb of Bistriopelma kiwicha sp. nov., holotype, $\widehat{\jmath}$ (MUBI 12). A. Prolateral view. B. Retrolateral view. Scale bars $=1 \mathrm{~mm}$. 
Table 3. Bistriopelma kiwicha sp. nov., holotype, $\widehat{\jmath}$ (MUBI 12); length of palpal and leg segments.

\begin{tabular}{lccccc}
\hline & Leg I & Leg II & Leg III & Leg IV & Palp \\
\hline Femur & 8.41 & 8.34 & 7.27 & 8.09 & 5.98 \\
Patellae & 5.45 & 4.11 & 3.17 & 4.00 & 3.14 \\
Tibiae & 6.31 & 5.18 & 5.88 & 6.00 & 4.72 \\
Metatarsus & 6.80 & 5.83 & 4.79 & 6.10 & - \\
Tarsus & 4.09 & 3.67 & 3.50 & 4.34 & 1.89 \\
Total & 30.35 & 27.83 & 23.33 & 27.42 & 16.09 \\
\hline
\end{tabular}

setae. Sternal sigillae small and narrow, located near coxa III (oval), II (circular) and I (oval). First pair of sigillae about three times of diameter from margin, second and third pair about two times of diameter from margin. Chelicerae with 10 teeth on promargin of furrow and absence of teeth on retromargin.

ABDOMEN. Urticating setae: Type III located in two dorsolateral patches with elongated golden setae (Fig 8D). Spinnerets: PMS, 0.81 long; PLS, three-segmented, 2.68 long.

LEGS AND PALPS. Leg formula: I > II > IV > III. All paired tarsal claws with 3-4 ventral teeth on each. Scopulae: Ventrally all tarsi fully scopulated. Tarsi I and II entire, III and IV divided by band of setae. Metatarsus I and II fully scopulated, III $3 / 4$ scopulated, IV $1 / 2$ scopulated. Dorsal face of all tarsi with two longitudinal rows of claviform trichobothria. Tibia I two-branched tibial apophysis: ventral branch with single strong apical spine and spiniform setae on inner side and prolateral branch with single inner strong spine, shorter than the branch. Metatarsus I contacts apex of ventral branch of tibial apophysis when flexed (Fig. 9C-E). Palps with cymbial lobes almost equal in sizes covered with long setae (Fig. 9A-B). Palpal tibia tapering to the apex.

SpINATION. Tarsi of legs I-IV 0. Femora: legs III and IV 0, palp 1p; legs: I 1d, II 2d. Patellae: palp and leg IV 0, I 1-1p, II 1-1p, III 1r (basal). Tibiae: palp 1p; legs: I 1-1p, 2-2r (apical), 1-2v; II 1-1p, 3-2-2v (apical); III 2-1-1p, 1-1r, 1-2-2v (apical), 1d; IV 2-1-1p (apical), 1-1r, 1-4v (apical). Metatarsi: I 1v (apical), II 1p, 1-1r (apical), 3v (apical); III 2-1-1-1-1p (apical), 2-2-1-1r, 1-3v (apical), 2d (apical); IV 1-1p (apical), 1-1r, 1-1-3v (apical), 1d.

PALPAL BULB. Bulb with narrow embolus projecting retrolaterally from tegulum, sigmoidly curved, and two distant well-developed keels, PS larger than PI (Fig. 10A-B). Tegulum long and with short domed basal projection (Fig. 10A).

Female (paratype, MUBI 41)

COLORATION. Live specimen: Carapace dark brown with reddish setae on margins; abdomen black with few red setae on proximal region and on dorsolateral patches of urticating setae; legs dark brown with reddish setae ventrally (Fig. 11A). In ethanol: Carapace light brown with pale setae on carapace margins; abdomen dark brown with two small dorsolateral patches of urticating setae, spinnerets brown; legs and sternum ventrally dark brown, labium and maxillae reddish brown (Fig. 12).

Measurements. Total length, without chelicerae and spinnerets: 18.14. Carapace: length 5.58, width 5.46. Abdomen: length 11.29. Clypeus: 0.07. Eye tubercle: length 0.75, width 0.67. Eyes sizes and interdistances: AME 0.08, ALE 0.15, PME 0.10, PLE 0.15, AME-AME 0.18, AME-ALE 0.07, PMEPME 0.36, PME-PLE 0.03, ALE-PLE 0.09. Labium: length 0.55, width 1.16. Sternum: length 2.58, width 2.45. Length of legs and palpal segments in Table 4. 
Cephalothorax. Carapace with deep procurved fovea and cephalic region raised (Fig. 12A-B). Anterior eye row straight and posterior eye row recurved (Fig. 12H). Labium with 9 cuspules (Fig. 12G). Maxillae with 79-83 (right/left) cuspules (Fig. 12G). Apical half of maxillae ventrally covered with short spiniform setae. Sternal sigillae oval located near coxa III, II and I. All sigillae distant about 2 diameters from margin. Chelicerae with 12 well-developed teeth on promargin of furrow and 9 very small tooth on retromargin.

ABDomen. Urticating setae: Type III located in two small dorsolateral patches almost inconspicuous (Figs 11A, 12E). Spinnerets: PMS, 0.70 long; PLS, three-segmented, 1.59 long.

LEGS AND PALPS. Leg formula: I > IV > II > III. All paired tarsal claws with 2-4 ventral teeth on each. Scopulae: Ventrally all tarsi fully scopulated, palp and leg I entire, legs II-IV divided by a band of setae. Metatarsi I $3 / 4$ scopulated, II $1 / 2$ scopulated, III $1 / 3$ scopulated, IV $1 / 4$ scopulated. Dorsal face of all tarsi with two longitudinal rows of claviform trichobothria.
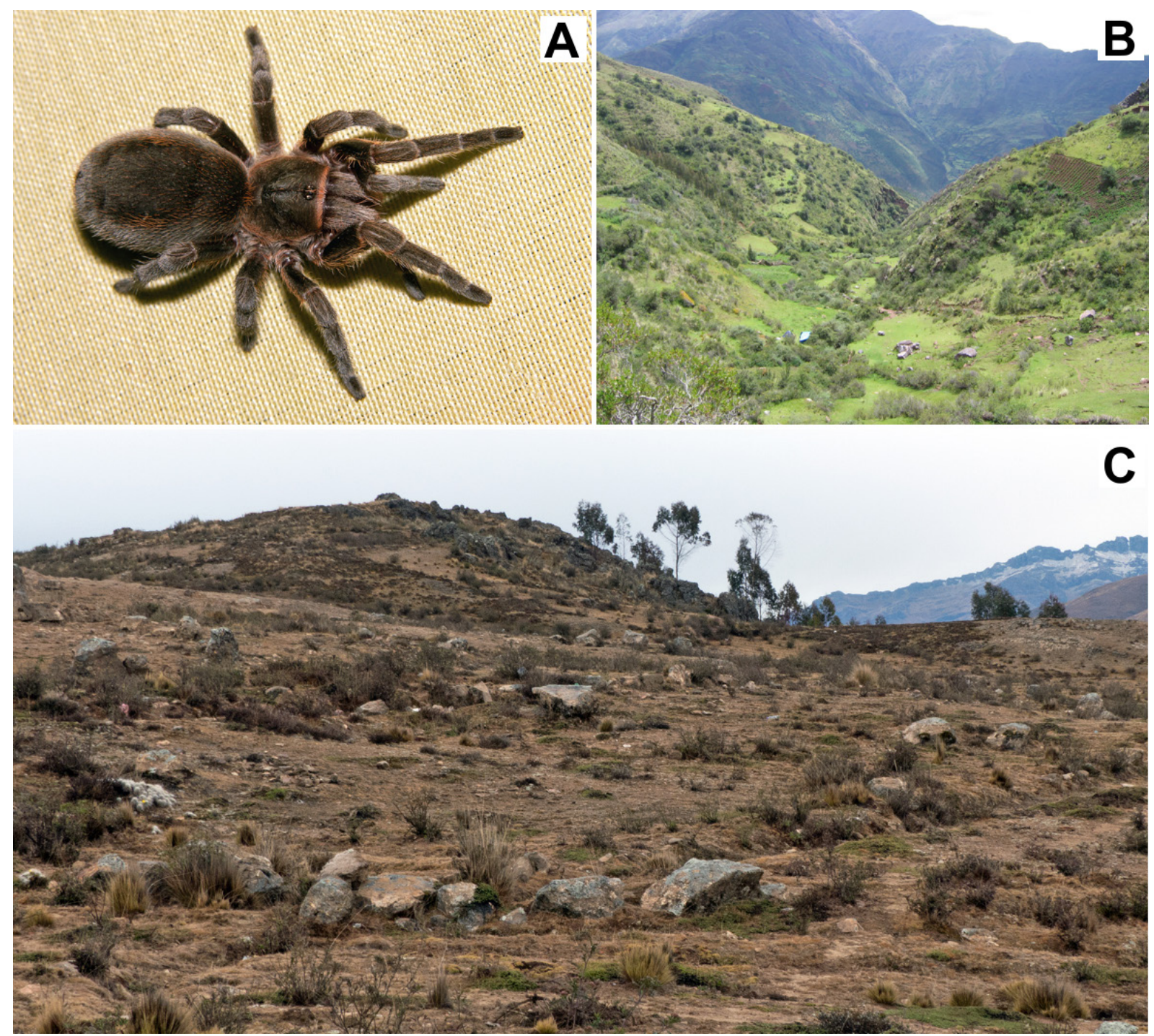

Fig. 11. Bistriopelma kiwicha sp. nov. A. Habitus, paratype, $q$ (MUBI 41). B. Habitat of male holotype in Peru, Llachoc. C. Habitat of female paratype in Peru, Cusco, Paucartambo, 3903 m.a.s.l. Photos: A, $\mathrm{C}=$ Rick C. West; $\mathrm{B}=$ José. A. Ochoa. 
Table 4. Bistriopelma kiwicha sp. nov., paratype, $q$ (MUBI 41); length of palpal and leg segments.

\begin{tabular}{lccccc}
\hline & Leg I & Leg II & Leg III & Leg IV & Palp \\
\hline Femur & 4.37 & 3.58 & 2.84 & 3.96 & 2.85 \\
Patellae & 2.87 & 2.22 & 2.00 & 2.42 & 1.90 \\
Tibiae & 2.57 & 2.02 & 1.59 & 2.04 & 2.07 \\
Metatarsus & 2.20 & 1.64 & 1.70 & 2.98 & - \\
Tarsus & 1.72 & 1.34 & 1.57 & 1.75 & 1.66 \\
Total & 13.73 & 10.80 & 9.70 & 13.15 & 8.48 \\
\hline
\end{tabular}

SPINATION. Femora, patellae and tarsi of legs I-IV and palps 0. Tibiae: palp 1v (apical), 1p (apical); legs I-IV 0. Metatarsi: I 1v (apical); II 1p, 1r, 1v (apical); III 1-1p, 1r, 1v; IV 1-1p, 1-1r, 1v (apical).

SPERmatheCA. Two fine-grained separated seminal receptacles with short ducts and distally ended with transverse oval lobe without ventral projections (Fig. 13).

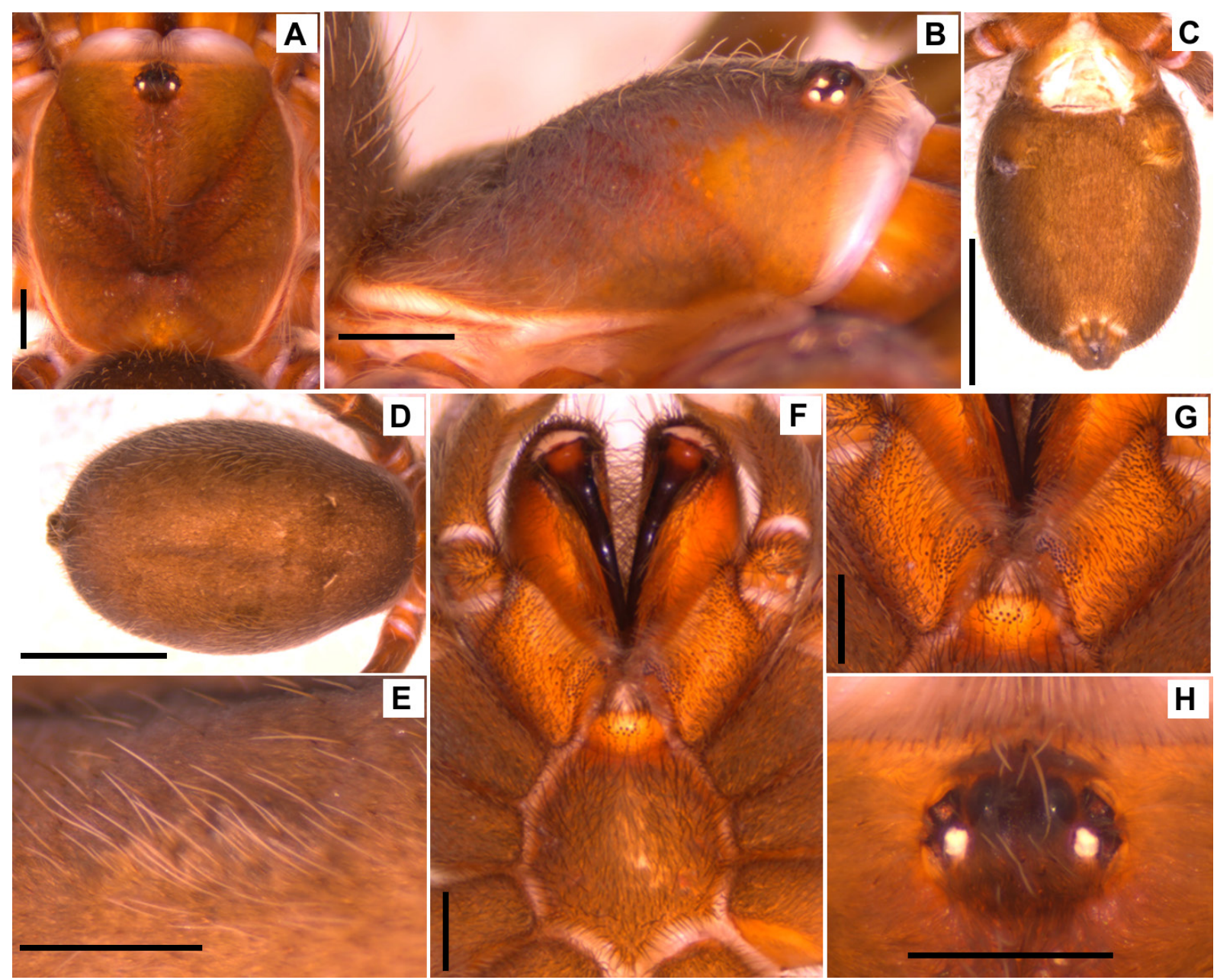

Fig. 12. Bistriopelma kiwicha sp. nov., paratype, $q$ (MUBI 41). A. Carapace, dorsal view. B. Carapace, lateral view. C. Abdomen, ventral view. D. Abdomen, dorsal view. E. Urticating setae patch. F. Sternum, labium and maxillae, ventral view. G. Labium and maxillae, ventral view. H. Eyes. Scale bars $=1 \mathrm{~mm}$. 


\section{Distribution and natural history}

Bistriopelma kiwicha sp. nov. is known from San Salvador and Paucartambo Provinces (Fig. 14), Department of Cusco, Peru, at elevations from 3570 to $3903 \mathrm{~m}$ a.s.l. and both locations are separated by $14 \mathrm{~km}$ in a straight line. The male specimen was collected during the rainy season (February). Female specimens were found on slopes of open Andean puna in self-made retreats under various-sized angular rocks lying on the surface of the ground. The area is partly covered with gallery forests of introduced pine and eucalyptus trees (Fig. 11B-C). Small villages with freely grazing llamas are also found throughout the habitat area.

\section{Discussion}

The genus Bistriopelma is distributed in the Puna and Queswa provinces in the Peruvian Andes (Ceballos-Bendezú 1976). So far, until the present contribution, it included just three species: B. lamasi from the Ayacucho Department, B. matuskai from the Apurimac Department and B. titicaca from the Puno Department (Kaderka 2015, 2017). The present study adds two new species to the genus: Bistriopelma peyoi sp. nov. and B. kiwicha sp. nov. The distribution area of B. peyoi sp. nov. is close to that of $B$. matuskai and both are recorded at high altitudes of more than $4000 \mathrm{~m}$ a.s.l. (Kaderka 2015). Bistriopelma kiwicha sp. nov. is the first species of Bistriopelma formally reported for Cusco Department and thus comprises the easternmost record of the genus in Peru and the lowest altitudinal

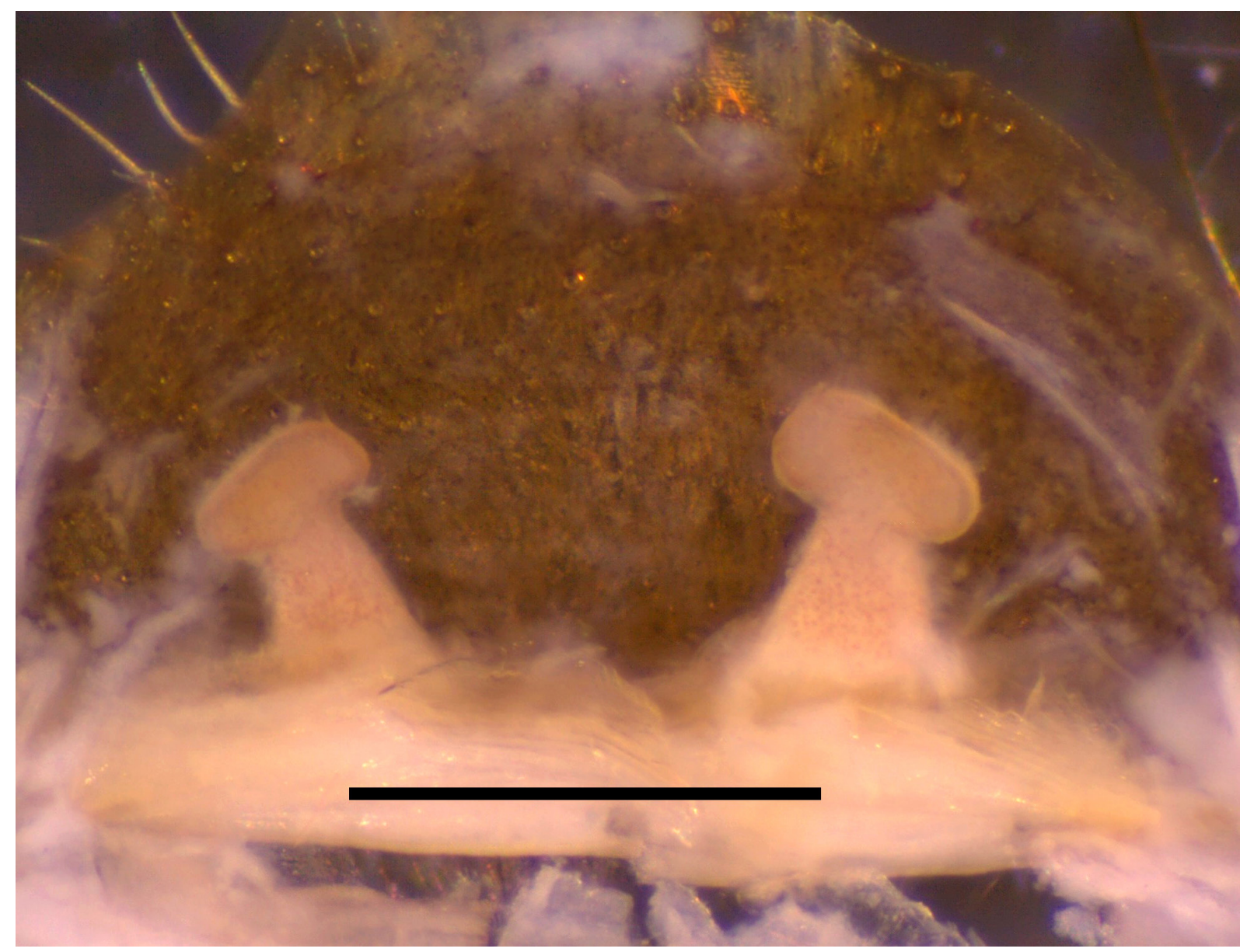

Fig. 13. Bistriopelma kiwicha sp. nov., paratype, $q$ (MUBI 41); spermathecae, dorsal view. Scale bar = $1 \mathrm{~mm}$. 
record for the genus. The typical habitat of the species described in the present work comprises shrub vegetation in the inter-Andean valleys and mountain grass slopes (Figs 5C, 11B-C) covered with stones under which spiders construct their burrows, similar to that found for the other species of Bistriopelma (Kaderka 2015).

The new species of Bistriopelma described here, B. peyoi sp. nov., is remarkable not only because of the foveal protuberance of the male but also by the absence of a fovea in the females. As far as we know, this is the first species with sexual dimorphism for the cephalic projection. The only approach of the function of the foveal protuberance or 'horn' was made by West (1986) studying African Ceratogyrus Pocock, 1897 specimens. This author assumed that there may be two primary functions of the foveal horn: first, to serve as an attachment site for the prominent muscles of the prosoma, mainly those attached to the sucking stomach; and second, to accommodate the expansion of the midgut diverticula for food storage (West 1986). However, for this species, dissection of specimens should be done in order to see which internal organs are inside the foveal horn space to examine whether its function is similar to that in Ceratogyrus, in particular because one species is from a somewhat hot xeric habitat and the other species from a cold xeric habitat. The discovery of this morphological feature in Bistriopelma led to four Neotropical genera of Theraphosinae that possess this remarkable character. Members of the other theraphosid genera from the Neotropics that also have similar foveal structures are Cyrtopholis Simon, 1892 (Caribbean), Sphaerobothria Karsch, 1879 (Costa Rica and Panama) and Umbyquyra Gargiulo, Brescovit \& Lucas, 2018 (Bolivia and Brazil). The other known genus of Theraphosidae that have a similar feature is the African Ceratogyrus (De Wet \& Dippenaar-Schoeman 1991; Peters 2000) as mentioned above. Recently, the new remarkable species C. attonitifer Engelbrecht, 2019 was described having a uniquely long soft protuberance (Midgley \& Engelbrecht 2019). However, the foveal protuberance found in the genus Bistriopelma is fully sclerotized, similar to that of all other genera where it is known to occur.

Unfortunately, this character is highly variable among species and now also appears to be variable among sexes. These structures range from almost absent to protruding projections on the back of the carapace (De Wet \& Dippenaar-Schoeman 1991; Gargiulo et al. 2018; Midgley \& Engelbrecht 2019) and their homology has not yet been studied among the various occurrences in Theraphosidae. It can

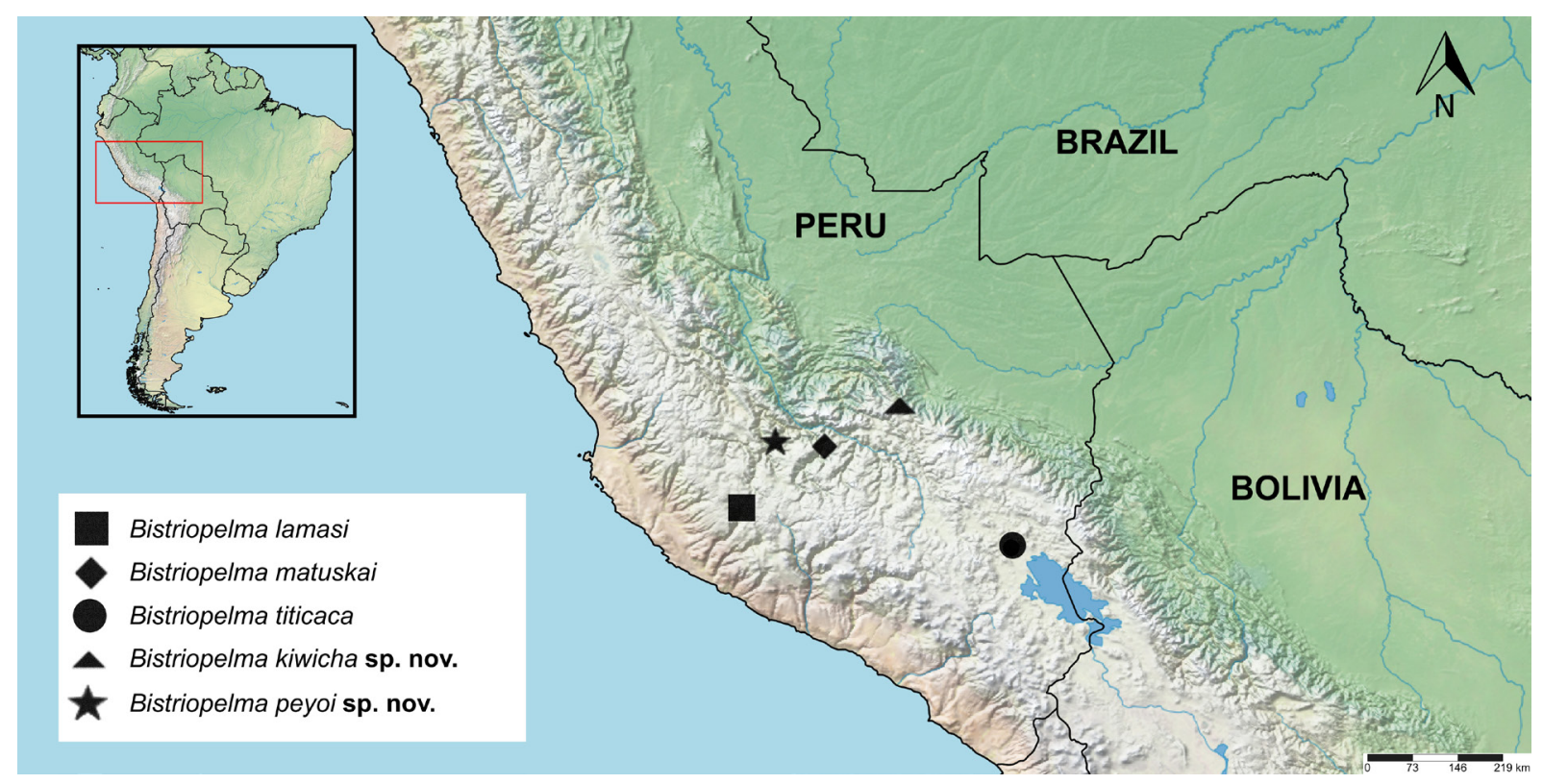

Fig. 14. Distribution map of the known species of Bistriopelma. 
thus hardly be used as diagnostic for some genera and should be treated as homoplastic, appearing as a convergence in a few species of Theraphosidae (Gallon 2001).

The discovery of these two new species highlights the relevance of inventories and taxonomic work yet to be carried out in Peru. In this way, this contribution is part of many future works that authors are conducting to describe the great theraphosid diversity found in Peru.

\section{Acknowledgements}

We are grateful to the staff of Museo de Biodiversidad del Perú, to Diana Silva Dávila (MUSM), Walter Silva Suárez, Josh Richards and Manuel Valladares for their help with collection permits or assistance in the field. All specimens described belong to the Museo de Biodiversidad del Perú (MUBI), which is recognized by the Resolución de Dirección General N 024-2017-SERFOR/DGGSPFFS. Also, thanks to Servicio Nacional Forestal y de Fauna Silvestre for collection permits \#332-2017-SERFOR/DGGSPFFS. N.F. is researcher at the National Council of Scientific and Technical Research (CONICET).

\section{References}

Bertani R. 2000. Male palpal bulbs and homologous features in Theraphosinae (Araneae: Theraphosidae). The Journal of Arachnology 28: 29-42. https://doi.org/10.1636/0161-8202(2000)028[0029:MPBAHF]2.0.CO;2

Bertani R. 2001. Revision, cladistic analysis, and zoogeography of Vitalius, Nhandu, and Proshapalopus; with notes on other theraphosine genera (Araneae, Theraphosidae). Arquivos de Zoologia 36 (3): 265-356.

Bertani R. \& Guadanucci J.P.L. 2013. Morphology, evolution, and usage of urticating setae by tarantulas (Araneae:Theraphosidae).Zoologia30(4):403-418.https://doi.org/10.1590/S1984-46702013000400006

Ceballos-Bendezú I. 1976. Nuevo esquema biogeográfico del Perú. Revista Universitaria - Universidad Nacional de San Antonio Abad del Cusco 130: 19-44.

Cooke J.A.L., Roth V.D. \& Miller F.H. 1972. The urticating hairs of theraphosid spiders. American Museum Novitates 2498: 1-43.

De Wet J.I. \& Dippenaar-Schoeman A.S. 1991. A revision of the genus Ceratogyrus Pocock (Araneae: Theraphosidae). Koedoe 34: 39-68. https://doi.org/10.4102/koedoe.v34i2.422

Gallon R.C. 2001. Revision of the Ceratogyrus spp. formerly included in Coelogenium (Araneae: Theraphosidae, Harpactirinae). Mygalomorph 2: 1-20.

Gargiulo F. de F., Brescovit A.D. \& Lucas S.M. 2018. Umbyquyra gen. nov., a new tarantula spider genus from the Neotropical region (Araneae, Mygalomorphae, Theraphosidae), with a description of eight new species. European Journal of Taxonomy 457: 1-50. https://doi.org/10.5852/ejt.2018.457

Guadanucci J.P.L. 2014. Theraphosidae phylogeny: relationship of the 'Ischnocolinae' genera (Araneae, Mygalomorphae). Zoologica Scripta 43: 518-518. https://doi.org/10.1111/zsc.12065

Kaderka R. 2015. Bistriopelma, a new genus with two new species from Peru (Araneae: Theraphosidae: Theraphosinae). Revista Peruana de Biología 22 (3): 275-288. https://doi.org/10.15381/rpb.v22i3.11432

Kaderka R. 2017. Description of the male of Bistriopelma matuskai Kaderka, 2015 and a new species of Bistriopelma from Peru (Araneae: Theraphosidae: Theraphosinae). Revista Peruana de Biología 24 (3): 231-242. https://doi.org/10.15381/rpb.v24i3.13904 
Midgley J.M. \& Engelbrecht I. 2019. New collection records for Theraphosidae (Araneae, Mygalomorphae) in Angola, with the description of a remarkable new species of Ceratogyrus. African Invertebrates 60 (1): 1-13. https://doi.org/10.3897/AfrInvertebr.60.32141

Pérez-Miles F., Lucas S.M., Da Silva P.I. \& Bertani R. 1996. Systematic revision and cladistic analysis of Theraphosinae (Araneae: Theraphosidae). Mygalomorph 1: 33-68.

Pérez-Miles F., Gabriel R., Miglio L., Bonaldo A., Gallon R., Jimenez J.J. \& Bertani R. 2008. Ami, a new theraphosid genus from Central and South America, with description of six new species (Araneae: Mygalomorphae). Zootaxa 1915: 54-68.

Peters H.J. 2000. Tarantulas of the World: kleiner Atlas der Vogelspinnen - Band 1. Published by the author.

Petrunkevitch A. 1925. Arachnida from Panama. Transactions of the Connecticut Academy of Arts and Sciences 27: 51-248.

West R. 1986. Ceratogyrus. Journal of the British Tarantula Society 1 (4): 79-80.

World Spider Catalog. 2019. World Spider Catalog. Version 20.5. Natural History Museum Bern. https://doi.org/10.24436/2

Manuscript received: 1 January 2020

Manuscript accepted: 24 March 2020

Published on: 12 May 2020

Topic editor: Rudy C.A.M. Jocqué

Desk editor: Radka Rosenbaumová

Printed versions of all papers are also deposited in the libraries of the institutes that are members of the EJT consortium: Muséum national d'histoire naturelle, Paris, France; Meise Botanic Garden, Belgium; Royal Museum for Central Africa, Tervuren, Belgium; Royal Belgian Institute of Natural Sciences, Brussels, Belgium; Natural History Museum of Denmark, Copenhagen, Denmark; Naturalis Biodiversity Center, Leiden, the Netherlands; Museo Nacional de Ciencias Naturales-CSIC, Madrid, Spain; Real Jardín Botánico de Madrid CSIC, Spain; Zoological Research Museum Alexander Koenig, Bonn, Germany; National Museum, Prague, Czech Republic. 